\title{
Lei de cotas e promoção da justiça social: percepções de estudantes cotistas de um instituto federal
}

\author{
Law of quotas and promotion of social justice: \\ perceptions of quota students from a federal institute \\ Ley de cuotas y promoción de la justicia social: \\ percepciones de estudiantes beneficiarios de un instituto federal
}

Fabiana Rodrigues de Sousa*
Ilca Freitas Nascimento**

\section{Resumo}

Este artigo apresenta reflexões resultantes de pesquisa de mestrado em Educação que objetivou dialogar com estudantes cotistas do curso de Engenharia Mecânica, a fim de desvelar suas percepções acerca da implementação da Lei n 12.711/2012. Para tanto, o percurso metodológico da investigação contemplou: análise documental referente ao processo de preenchimento de vagas do curso; contato telefônico com discentes para identificar causas de suas desistências; aplicação de questionário para levantamento de dados socioeconômicos; e realização de entrevistas. Na percepção dos cotistas, a reserva de vagas garantida pela Lei n 12.711/2012 pode ampliar a oportunidade de acesso para estudantes de escolas públicas, com baixa renda, afrodescendentes e indígenas. No entanto, para que a lei de cotas se configure como promotora de justiça social, é necessário, ainda, o enfrentamento a alguns desafios, quais sejam: a) não se limitar a aspectos de acesso, mas ampliar medidas que favoreçam a permanência destes estudantes; b) avaliar o modo como cotistas são recebidos e acolhidos por seus pares, docentes e funcionários das instituições de ensino; c) desenvolver mecanismos de acompanhamento e apoio do desempenho acadêmico, didático e psicopedagógico dos estudantes; d) aumentar recursos do Programa Nacional de Assistência Estudantil; e) melhorar a qualidade da educação básica em escolas públicas.

Palavras-chave: Ação afirmativa. Ensino superior. Justiça social. Lei de cotas.

Recebido em 06/04/2019 - Aprovado em 02/07/2019

http://dx.doi.org/10.5335/rep.v26i3.9301

Doutora em Educação, com estágio pós-doutoral no Centro de Educação e Ciências Humanas da Universidade Federal de São Carlos. Educadora popular e docente do Programa de Mestrado em Educação Sociocomunitária do Centro Universitário Salesiano de São Paulo. Brasil. ORCID: 0000-0001-9963-0958. E-mail: fabiana.sante@unisal.br

** Mestre em Educação pelo Centro Universitário Salesiano de São Paulo. Atua como assistente social. Brasil. ORCID: 0000-0002-6353-6940. E-mail: ilca.ifsp@gmail.com 


\section{Abstract}

This article presents reflections resulting from a Master's Degree in Education that aimed to dialogue with quota students attending the Mechanical Engineering course in order to unveil their perceptions about the implementation of Law 12.711/2012. The research methodology contemplated documentary analysis referring to the process of filling vacancies of the course; telephone contact with students to identify causes of their dropouts; application of a questionnaire to collect socioeconomic data and interviews. In the perception of the quota students, the reserve of vacancies guaranteed by Law 12.711/2012 can increase the opportunity of access for students of public schools, with low-income, Afro-descendants and indigenous. However, in order for the quota law to become a promoter of social justice, it is also necessary to face certain challenges: a) not be limited to aspects of access, but expand measures that favor the permanence of these students; $b$ ) to evaluate how quota students are received by their peers, teachers and employees of the educational institutions; $c$ ) develop mechanisms to monitor and support students' academic, didactic and psychopedagogical performance; d) increase resources of the National Program of Student Assistance; e) improve the quality of basic education in public schools.

Keywords: Affirmative action. Higher education. Social justice. Law of quota.

\section{Resumen}

Este artículo presenta reflexiones resultantes de una investigación a nivel de Maestría en Educación que objetivó dialogar con estudiantes beneficiarios del programa de cuotas en el curso de Ingeniería Mecánica a fin de desvelar sus percepciones acerca de la implementación de la Ley 12.711. Para tanto, el recorrido metodológico de la investigación contempló análisis documental referente al proceso de admisión del alumnado beneficiario del programa de cuotas; contacto telefónico con discentes para identificar los motivaciones de sus salidas del curso; la aplicación de cuestionario para el levantamiento de datos socioeconómicos y la realización de entrevistas. En la percepción de los beneficiarios, la reserva de plazas garantizada por la Ley 12.711 puede ampliar la oportunidad de acceso para estudiantes de escuelas públicas, con bajos ingresos, afro descendientes e indígenas. Sin embargo, para que la ley de cuotas se configure como promotora de justicia social es necesario, todavía, el enfrentamiento a algunos desafíos, que: a) no se limiten a aspectos de acceso, sino a ampliar medidas que favorezcan la permanencia de estos estudiantes; b) evaluar el modo en que los beneficiarios son recibidos y acogidos por sus pares, docentes y funcionarios de las instituciones de enseñanza; c) desarrollar mecanismos de acompañamiento y apoyo del desempeño académico, didáctico y psicopedagógico de los estudiantes; d) aumentar recursos del Programa Nacional de Asistencia Estudiantil; e) mejorar la calidad de la educación básica en las escuelas públicas.

Palabras claves: Acción afirmativa. Enseñanza superior. Justicia social. Ley de cuotas.

\section{Introdução}

O acesso ao ensino superior, no Brasil, correlaciona-se às trajetórias sociais, econômicas e culturais com as quais os indivíduos convivem no percurso da vida. Em um país fortemente marcado por desigualdades na distribuição de bens econômicos, sociais e culturais e com acirrada concorrência por vagas, a chance de ingresso em uma instituição pública de ensino superior acaba tornando-se viável a uma parcela restrita da população. Somente classes sociais privilegiadas economicamente detêm poder aquisitivo para custear mensalidades em conceituadas ins- 
tituições de educação básica, viagens, cursos de línguas estrangeiras, participação em seminários e oficinas, entradas em museu, teatro, cinema, etc. De acordo com Gisi (2006), os problemas de acesso e permanência na educação superior são efeitos, e não o fator das desigualdades - que têm relação com as condições existenciais vivenciadas por cada classe e grupo étnico e com os distintos modos pelos quais se apropriam dos bens culturais.

[...] o legado de bens culturais acumulados e transmitidos pelas gerações anteriores pertence, realmente (embora seja formalmente oferecido a todos), aos que detêm os meios para dele se apropriarem, quer dizer, que os bens culturais, enquanto bens simbólicos, só podem ser apreendidos e possuídos como tais (ao lado das satisfações simbólicas que acompanham tal posse) por aqueles que detêm o código que permite decifrá-los (BOURDIEU, 2003, p. 297).

Nesse sentido, urge a necessidade de reiterar a relevância social de políticas e ações afirmativas, com a finalidade de democratizar o acesso ao ensino superior público, bem como de garantir condições de permanência para estudantes universitários. A ampliação do acesso ao ensino superior teve um desdobramento relevante nos últimos oito anos que se seguem a 2004. Estudos realizados pelo Grupo Estratégico de Análise da Educação Superior no Brasil ${ }^{1}$ apontam que, nesse intervalo de tempo, passou-se de 4,2 milhões de matrículas para 6,7 milhões, segundo o Censo da educação superior: 2011 - resumo técnico, do Instituto Nacional de Estudos e Pesquisas Educacionais Anísio Teixeira (2013). Isto é, houve um acréscimo significativo de novos estudantes em cursos superiores no Brasil (BUCCI; MELLO, 2013).

Uma série de providências influenciou o alcance deste resultado; dentre elas, destacam-se a política de reestruturação das universidades federais e o aumento de vagas, a partir da criação de cursos noturnos e da abertura de campi em cidades do interior, frutos do Programa de Apoio a Planos de Reestruturação e Expansão das Universidades Federais (Reuni). Juntamente, houve uma expansão dos Institutos Federais de Educação, Ciência e Tecnologia (IF), ofertando principalmente cursos técnicos. Também foi formada a Universidade Aberta do Brasil, um programa que oferece cursos de nível superior, por meio da metodologia da educação a distância (BUCCI; MELLO, 2013).

Nos últimos decênios, muitos jovens e adultos brasileiros negros, indígenas e/ou de baixa renda ingressaram no ensino superior como consequência de variadas políticas de democratização que contemplaram instituições de ensino públicas, federais e estaduais e também instituições privadas. Dentre essas medidas, destaca-se o Exame Nacional do Ensino Médio (Enem), criado em 1998, que tem como objetivos avaliar o desempenho do estudante ao fim da escolaridade básica e 
articulá-lo ao Sistema de Seleção Unificada (Sisu), que é o sistema informatizado, gerenciado pelo Ministério da Educação (MEC), no qual instituições públicas de ensino superior oferecem vagas para candidatos participantes do Enem.

Além dele, há também o Programa Universidade Para Todos (Prouni), regulamentado pela Lei $\mathrm{n}^{\circ}$ 11.096, de 13 de janeiro de 2005, que concede bolsas de estudo integrais e parciais (50\%) em instituições privadas de ensino superior; o Fundo de Financiamento Estudantil (Fies), que foi criado em 1999 e constitui-se como programa do MEC destinado à concessão de financiamento a estudantes de cursos superiores em instituições privadas de ensino, as quais se beneficiam obtendo isenção de impostos; e o Plano Nacional de Assistência Estudantil (PNAES), que tem por objetivo apoiar a permanência de estudantes em situação de vulnerabilidade socioeconômica e destina-se prioritariamente a estudantes com renda per capita de até um salário mínimo e meio.

O PNAES ${ }^{2}$ garante autonomia aos IFs para empregarem os recursos conforme suas demandas e especificidades locais. Além da oferta de bolsas, o plano favorece articulação de diversas áreas (assistência, educação, habitação, etc.), com o intuito de gerar estratégias para melhorar o desempenho acadêmico dos estudantes (PRADA; SURDINE, 2018).

Há, ainda, a Lei $\mathrm{n}^{\circ}$ 12.711, regulamentada pelo Decreto $\mathrm{n}^{\circ} 7.824$, de 11 de outubro de 2012. A lei tem como finalidade ampliar as oportunidades de ingresso no ensino superior, bem como no ensino técnico de nível médio, com vistas a democratizar as condições de acesso, minimizar os efeitos das desigualdades sociais e étnico-raciais, contribuindo, portanto, com a promoção da justiça social por meio da educação.

Ressalta-se que a promoção da justiça social pressupõe mais do que o acesso ao ensino superior, uma vez que requer o planejamento e a execução de condições de permanência (materiais, físicas e psicológicas) adequadas aos estudantes. Observa-se que a entrada de segmentos sociais historicamente excluídos do acesso ao ensino superior - seja nas instituições públicas, a partir da expansão de novos campi e polos de educação a distância, assim como da criação de novas universidades; seja nas instituições privadas, a partir da política de bolsas parciais ou integrais e do financiamento estudantil, sem que haja o devido cuidado com as condições de permanência desses estudantes - pode contribuir para alguns fatos, como: o aumento no número de ingressos não repercutir no número de formandos, tendo como efeito o problema da evasão; a vida universitária reduzir-se às vivências em sala de aula, com o tempo sendo concorrido entre os estudos e o trabalho, com isso refletindo no 
problema pedagógico formativo; as ações formativas acompanharem o modelo tradicional de ensino, não levando em conta o universo cultural das classes populares, acarretando problemas epistemológicos (PEREIRA; MAY; GUTIERREZ, 2014).

Destarte, o objetivo do presente artigo consiste em desvelar percepções de estudantes cotistas sobre a implementação da chamada lei de cotas, sobretudo, aspectos ligados ao acesso e à permanência desses estudantes no ensino superior, com o intuito de compreender se a lei tem favorecido à promoção das justiças social e educacional. As considerações, ora apresentadas, foram gestadas ao longo de pesquisa de Mestrado em Educação, concluída em 2016, e pautam-se em percepções de estudantes cotistas do curso de Engenharia Mecânica, de um IF localizado no interior do estado de São Paulo.

\section{Ação afirmativa e justiça social}

No Brasil, as políticas públicas historicamente se caracterizam pelo cunho social, com medidas e ações voltadas ao combate à pobreza. Moehlecke (2002) ressalta que, com a popularização do país, alguns movimentos sociais começaram a unir forças e pressionar o Poder Público a ter uma participação mais ativa na resolução de problemas específicos em função de questões de gênero, raça e etnia, culminando na formulação de diferentes ações afirmativas.

As ações afirmativas consistem em ações reparatórias e/ou preventivas que possuem o objetivo de corrigir os efeitos "de discriminação e desigualdade infringida a certos grupos no passado, presente ou futuro, através da valorização social, econômica, política e/ou cultural desses grupos, durante um período limitado" (MOEHLECKE, 2002, p. 203).

O termo ação afirmativa foi cunhado inicialmente nos Estados Unidos ${ }^{3}$, local que ainda hoje se constitui como importante referência no assunto. Na década de 1960, os estadunidenses atravessavam um período de reivindicações democráticas expressas, principalmente no movimento pelos direitos civis que pleiteava ampliação da igualdade de oportunidades a todos. Neste espaço de tempo, são questionadas as leis segregacionistas vigentes no país, e o movimento negro aparece como uma importante força atuante, com lideranças de projeção nacional, apoiado por progressistas brancos e liberais reunidos numa ampla defesa de direitos. É nesse âmbito que aparece o conceito de ação afirmativa, reivindicando que o Estado garanta leis antissegregacionistas tomando uma postura atuante para viabilizar melhores condições de vida à população negra (MOEHLECKE, 2002). 
Essa experiência dos Estados Unidos com a implantação de políticas de ações afirmativas enfaticamente raciais pode suscitar reflexões e contribuições para implementação de tais políticas no Brasil. Munanga (2001) apregoa que as ações afirmativas não devem se pautar somente em critérios econômicos e nas desigualdades de classe, é necessário considerar também o critério racial e as especificidades culturais de cada grupo étnico, a fim de promover a justiça social. No excerto seguinte, o autor elucida por que o marcador racial é tão relevante na construção da justiça educacional.

[...] se por um passe de mágica, os ensinos básico e fundamental melhorassem seus níveis para que os alunos pudessem competir igualmente no vestibular com os estudantes oriundos dos colégios particulares bem abastecidos, os alunos negros levariam cerca de 32 anos para atingir o atual nível dos alunos brancos. Isso supõe que os brancos fiquem parados em suas posições atuais esperando a chegada dos negros, para juntos caminharem no mesmo pé de igualdade. Uma hipótese improvável, melhor, inimaginável. Os lobbies das escolas particulares cada vez mais fortes deixarão os colégios públicos subirem seu nível de ensino, tendo como conseqüência a redução de sua clientela majoritariamente oriunda das classes sociais altas e médias e a diminuição de seus lucros? Quanto tempo a população negra deverá ainda esperar essa igualdade de oportunidade de acesso e permanência a um curso superior ou universitário gratuito e de boa qualidade? (MUNANGA, 2001, p. 33).

Lima, Neves e Silva (2014) ratificam o exposto por Munanga (2001) e ressaltam que o campo das relações raciais ocupa lugar de destaque no estudo das percepções de justiça/injustiça e de legitimação/contestação da ordem vigente, devido à forte assimetria de poder e dominação que tem caracterizado essas relações ao longo da história.

O debate sobre a implantação de políticas de ações afirmativas levanta preocupações com a justiça. Os julgamentos sobre a justiça fazem a mediação entre as circunstâncias objetivas e as reações das pessoas aos eventos particulares de tal forma que o modo como os cidadãos comuns avaliam as normas, se justas ou injustas, é um tema de interesse especial para as ciências sociais, pois os padrões de justiça são resultado dos processos de construção da realidade social (LIMA; NEVES; SILVA, 2014, p. 143).

Adicionalmente, Fraser (2009) observa que mudanças vêm ocorrendo nas discussões sobre justiça social, uma vez que teorias monológicas, cada vez mais, vêm sendo questionadas e rejeitadas, e teóricos têm adotado abordagens dialógicas, que tratam de aspectos importantes da justiça, como a tomada de decisão coletiva por meio de deliberação democrática. Para esses teóricos, "a gramática da teoria da justiça está sendo transformada. O que poderia antes ser chamado de 'teoria da justiça social' agora aparece como 'teoria da justiça democrática”' (FRASER, 2009, p. 36). Todavia, a teoria da justiça democrática permanece incompleta e, para ser 
concluída, é necessário um passo além, ou seja, é preciso considerar, nos processos democráticos, não apenas o "que" da justiça, mas também o "quem" e o "como"; por isso a autora defende que "as teorias da justiça devem-se tornar tridimensionais, incorporando a dimensão política da representação ao lado da dimensão econômica da distribuição e da dimensão cultural do reconhecimento” (FRASER, 2009, p. 17, grifo da autora).

A consolidação da justiça social requer arranjos que estimulem a participação de todos os sujeitos, em condições de paridade, na construção da vida social; portanto, a superação da injustiça reclama o desmanche de obstáculos que dificultam a plena participação (FRASER, 2009).

A permanência das segregações social e racial de jovens negros e pobres, no Brasil, pode ser tomada como um exemplo de obstáculo que dificulta a participação desses sujeitos sociais e reduz suas possibilidades de acessar seus direitos, legitimando a perpetuação da injustiça social. Nesse sentido, Arroyo (2015) retoma o pensamento do historiador Eric Hobsbawm e defende a adoção de uma postura ético-política que permita abarcar não somente os obstáculos enfrentados, mas, sobretudo, as resistências desses sujeitos. A análise histórica do processo de negação-afirmação do direito à educação não pode prescindir, pois, dessa postura ético-política.

De acordo com Arroyo (2015), essa análise histórica pode seguir caminhos distintos. O primeiro deles, comumente trilhado, tem como foco o questionamento acerca do papel do Estado no cumprimento de leis, diretrizes e políticas destinados à garantia do direito à educação. Nessa perspectiva, os sujeitos educativos - pessoas pobres, negros, indígenas e trabalhadores explorados - figuram como destinatários, e não como construtores de políticas públicas.

Por sua vez, o segundo caminho, nas palavras do autor, centra-se em uma análise política mais complexa, que consiste, portanto, em:

[...] tentar entender a negação-afirmação do direito à educação no padrão de poder-saber que perpassa as tensas relações das elites com os grupos sociais étnicos, raciais, subalternizados, oprimidos em nossa história. Nessa opção de análise, duas questões serão o ponto de partida: a primeira, reconhecer que as possibilidades e os limites da garantia de seus direitos estiveram condicionados em nossa história a como esses grupos sociais, raciais foram pensados e alocados no padrão de poder-dominação-subalternização. A segunda, reconhecer também que as formas como os grupos sociais, raciais subalternizados resistem a esse padrão de poder-saber vêm sendo determinantes das possibilidades de avanço na garantia de seus direitos (ARROYO, 2015, p. 17). 
Nessa perspectiva analítica política, não é possível denunciar a injustiça social, tampouco anunciar possibilidades de justiça social, sem levar em consideração experiências, percepções, saberes e resistências dos grupos sociais oprimidos nos contextos de seus movimentos e lutas por direitos. Reside, aqui, a intrínseca relação entre o conceito de justiça social e a formulação de ações afirmativas, tais como a política de cotas, que é entendida como:

[...] uma política que se baseia no argumento de que a sub-representação de minorias em instituições e posições de maior prestígio e poder na sociedade é um reflexo da discriminação. Esta visa, em caráter provisório, à criação de incentivos a grupos desfavorecidos para beneficiar os alunos que provêm de camadas populares, com baixo poder econômico, geralmente oriundos de escolas públicas, ou minorias étnicas, destacando o fato de que, muitas vezes, esses alunos têm necessidades específicas para sua integração e permanência nos espaços universitários (SOUZA; BRANDALISE, 2015, p. 187).

Alçada nessa concepção de política de cotas, em outubro de 2012, após uma década de intensas discussões e lutas travadas principalmente pelos movimentos sociais negros, foi publicada a Lei $\mathrm{n}^{0} 12.711$ (BRASIL, 2012a), sancionada pela presidenta Dilma Rousseff, cuja regulamentação veio com o Decreto no 7.824 (BRASIL, 2012c) e a Portaria Normativa $n^{\circ} 18$ (BRASIL, 2012b), ambos de 11 de outubro de 2012. A lei de cotas privilegia estudantes de escola pública e alia critérios étnico-raciais aos socioeconômicos, fixando a obrigatoriedade da reserva de $50 \%$ de todas as vagas nas instituições federais de ensino para estudantes de escolas públicas, com subcotas para aqueles cujas famílias possuem renda per capita igual ou inferior a um salário mínimo e meio; e/ou autodeclarados pretos, pardos ou indígenas (BRASIL, 2012a; 2012b).

Por sua vez, o Decreto n⿳⺈ 7.824/2012 estabelece reserva de vagas a partir de três critérios: origem da escola pública, renda familiar per capita e etnia/raça do candidato. O decreto garante a reserva de $50 \%$ das matrículas por curso e turno a alunos oriundos integralmente do ensino médio público. Os outros $50 \%$ das vagas permanecem para ampla concorrência. $\mathrm{O}$ total de vagas reservadas às cotas será subdividido da seguinte forma: metade para estudantes de escolas públicas com renda familiar bruta igual ou inferior a um salário mínimo e meio per capita e metade para estudantes de escolas públicas com renda familiar superior a um salário mínimo e meio per capita. Em ambos os casos, também será levado em conta percentual mínimo correspondente ao da soma de pretos, pardos e indígenas, baseado no último censo demográfico do Instituto Brasileiro de Geografia e Estatística de cada região. 


\section{A reserva de vagas na instituição pesquisada e o percurso metodológico}

As reflexões apresentadas neste estudo foram elaboradas em contexto de pesquisa realizada em diálogo com estudantes cotistas do curso de Engenharia Mecânica de um IF localizado no interior do estado de São Paulo. Os IFs surgem no final do ano de 2008, instituídos pela Lei no 11.892, de 29 de dezembro de 2008, com o objetivo de ofertar educação profissional e tecnológica em todos os seus níveis e modalidades, mas estas instituições de ensino se originam historicamente ainda em 1909, com a fundação da Escola de Aprendizes e Artífices de São Paulo.

O diferencial dos IFs de São Paulo, evidenciado no Plano de Desenvolvimento Institucional (2014-2018), é o desenho curricular, cuja proposta político-pedagógica possibilita a oferta de todos os níveis de ensino, desde a educação básica, em especial cursos técnicos, integrados e modulares, até o ensino superior (graduação e pós-graduação). Fazem parte dos institutos cursos superiores de tecnologia, licenciaturas, bacharelados e programas de pós-graduação (especialização, mestrado e doutorado). Uma característica marcante é a inserção na área de pesquisa e extensão, visando a estender benefícios à comunidade, além da formação continuada de trabalhadores.

O percurso metodológico da investigação contemplou: análise documental referente aos processos de seleção e preenchimento de vagas do curso; contato telefônico com discentes, para identificar causas de suas desistências; aplicação de questionário, para levantamento de dados socioeconômicos; e realização de entrevistas com quatro estudantes cotistas, a fim de mapear suas percepções acerca da lei de cotas.

Inicialmente, foi realizada análise dos dados fornecidos pela Coordenadoria de Registros Escolares do IF, com o objetivo de investigar se as 20 vagas reservadas para o sistema de cotas do curso de Engenharia Mecânica foram preenchidas, visto que, não havendo procura, as vagas são disponibilizadas para a ampla concorrência. A seleção de estudantes para se matricular nas vagas dos cursos de graduação oferecidos pelos IFs é realizada por meio do Sistema de Seleção Unificada e considera os resultados obtidos pelos estudantes no Enem.

Constatou-se que, no curso de Engenharia Mecânica, foram efetuadas 1.579 inscrições para a chamada regular única; dessas, somente os 40 primeiros candidatos por ordem de pontuação e por categoria foram convocados, sendo 20 candidatos para as vagas de ampla concorrência e 20 candidatos para as vagas de ação afirmativa. Com base nos dados fornecidos pela Coordenaria de Registros Escolares, 
observou-se que, dos 20 candidatos convocados na chamada regular única para preencher as vagas das cotas, somente 10 candidatos efetivaram a matrícula; e, da ampla concorrência, somente 4 candidatos efetivaram a matrícula no curso. Em razão disso, houve mais candidatos cotistas do que não cotistas que efetivaram a matrícula nesse primeiro momento. No entanto, cabe ressaltar que a reserva de vagas foi realizada apenas na primeira chamada regular, as 26 vagas remanescentes (16 da ampla concorrência e 10 das cotas) que foram sendo preenchidas em outras chamadas, conforme lista de espera disponibilizada pelo Sisu, passaram a ser ofertadas à ampla concorrência e foram preenchidas obedecendo somente à classificação por pontuação pela nota final.

Entre os 10 candidatos cotistas que efetivaram a matrícula: 5, independentemente da renda, cursaram integralmente o ensino médio em escola pública; 2 candidatos da categoria de renda familiar baixa cursaram integralmente o ensino médio em escola pública; 2 candidatos autodeclarados pretos, pardos ou indígenas e com renda familiar baixa cursaram integralmente o ensino médio em escola pública; e 1 candidato autodeclarado preto, pardo ou indígena, independentemente da renda, cursou integralmente o ensino médio em escola pública.

No entanto, 5 estudantes cotistas, todos moradores de outros municípios do estado de São Paulo, solicitaram o cancelamento da matrícula logo após o início das aulas. Os motivos dos cancelamentos foram averiguados por contato telefônico com cada estudante, e constatou-se que todos optaram por estudar engenharia em outras instituições de ensino superior. Verificaram-se os seguintes casos: 2 relataram que optaram por cursar engenharia (1 de produção e 1 de materiais) na Universidade Federal de São Carlos, que possui alojamento estudantil; e 3 optaram por cursar engenharia ( 2 mecânica e 1 elétrica) em universidades privadas com bolsa do Prouni, o que os mantinha próximos de suas famílias, bem como representava uma economia com despesas de moradia. É importante ressaltar que o IF em que foi realizada a pesquisa não possui alojamento estudantil.

Esses cinco estudantes foram convidados a participar da pesquisa e responderam um questionário para ilustrar seu perfil socioeconômico. Entre eles, quatro são do sexo masculino, e uma, do sexo feminino, e apresentavam idades entre 18 e 19 anos. Três se autodeclararam brancos; um, negro; e um, pardo. Todos eram solteiros, não possuíam filhos e apresentavam renda familiar superior a dois salários mínimos: três estudantes possuíam renda mensal de dois a quatro salários, e dois estudantes, renda mensal maior do que cinco salários mínimos. Três estudantes tiveram que se mudar, pois moravam em cidades distantes do munícipio onde 
se localiza o IF, e passaram a residir em repúblicas. Apenas um dos estudantes mencionou que exercia, concomitante ao curso, atividade remunerada: distribuía panfletos em farol, a fim de obter renda para auxiliar o custeio da sua manutenção na nova cidade.

Ao fim do primeiro semestre letivo do curso, mais um estudante cotista - autodeclarado pardo - efetivou trancamento de matrícula. Por meio de contato telefônico, o estudante informou que sua principal dificuldade foi a socialização, uma vez que não conseguia adaptar-se à nova cidade e fazer amigos no instituto e na república em que morava. Sendo assim, apenas quatro estudantes participaram das entrevistas, que foram realizadas após o início do segundo semestre letivo do curso.

A entrevista possibilita conhecer a experiência vivida e apreender como distintos sujeitos vivem determinada condição comum a eles. Assim, as pesquisas que fazem uso da entrevista tomam como ponto de partida sempre aquilo que o informante diz, pois isso é a matéria-prima:

[...] muito do que nos é dito é profundamente subjetivo, pois trata-se do modo como aquele sujeito observa, vivencia e analisa seu tempo histórico, seu momento, seu meio social etc.; é sempre um, entre muitos pontos de vista possíveis. Assim, tomar depoimentos como fonte de investigação implica extrair daquilo que é subjetivo e pessoal neles o que nos permite pensar a dimensão coletiva, isto é, que nos permite compreender a lógica das relações que se estabelecem (estabeleceram) no interior dos grupos sociais dos quais o entrevistado participa (participou), em um determinado tempo e lugar (DUARTE, 2004, p. 219).

A adoção de entrevistas pautadas no enfoque fenomenológico favoreceu o desvelamento das percepções que os estudantes cotistas possuíam a respeito das políticas de cotas, configurando-se como procedimento metodológico viável para os fins da investigação desenvolvida, a qual procurou gerar dados para suprir uma lacuna apontada por Lima, Neves e Silva (2014). Os autores denunciam que são poucos os estudos que se dispuseram a enfocar a evolução das atitudes em relação ao sistema de cotas antes e depois de sua implantação, como se ocuparam os trabalhos desenvolvidos por Neves e Lima (2007), Lima, Neves e Silva (2014) e Queiroz e Santos (2006).

Estudos que se propõem a identificar interpretações, sentidos e significados que estudantes universitários nutrem a respeito da implementação do sistema de cotas na reserva de vagas nas universidades brasileiras podem trazer contribuições relevantes no sentido de ampliar a compreensão acerca do porquê de alguns setores ainda se opor às cotas e negar o caráter de justiça que subjaz à aplicação das ações afirmativas. Pesquisas dessa natureza explicitam que a definição do que 
é considerado justo ou injusto em uma sociedade é uma questão política, assim como o é o próprio ato educativo (NEVES; LIMA, 2007).

\section{As percepções de estudantes cotistas acerca da lei de cotas}

Sou a favor, sou bem a favor da lei de cotas porque, levando em conta toda a desigualdade que a gente tem na sociedade, é difícil. É difícil não, é impossível tratar todo mundo igualmente sendo que não tem igualdade. Então, assim, eu acho que o sistema de cotas não deve seguir para sempre, claro que não, vai chegar num ponto que vai atingir uma igualdade, que, aí, você não vai mais precisar disso; enquanto tem desigualdade, você precisa tratar as situações de acordo com as desigualdades que acontecem.

Este depoimento, cedido por um participante da pesquisa, sintetiza a percepção dos quatro estudantes cotistas entrevistados acerca da reserva de vagas garantida pela Lei $\mathrm{n}^{\circ}$ 12.711/2012. Para eles, a lei de cotas apresenta-se como dispositivo capaz de ampliar a oportunidade de acesso ao ensino a estudantes de escolas públicas, com baixa renda, afrodescendentes e indígenas; no entanto, para que seja possível concretizar a justiça educacional, é necessário que também sejam tomadas medidas para melhorar a qualidade da educação básica, concomitantes a execução e avaliação de ações afirmativas, pois, sem o investimento na melhoria da educação básica, não há como viabilizar o caráter temporário que deve permear as políticas afirmativas.

Todos os participantes reconheceram a existência de um contexto de desigualdade econômica no país, que culmina em oportunidades desiguais no acesso e na garantia de direitos, sobretudo, do direito à educação. Essa desigualdade se evidencia no início da escolarização, na distinção qualitativa da educação básica que é ofertada na rede pública em relação à que é oferecida na rede privada, pois comumente os estudantes que conseguem acessar o ensino superior público - sem fazer uso de ações afirmativas - são aqueles advindos de escolas privadas, enquanto que os estudantes que desenvolveram integralmente sua escolaridade em instituições de ensino públicas apresentam maiores dificuldades para ingressar em universidades públicas.

Frente a esse contexto, os participantes da pesquisa entendem que, para superar essa realidade, é necessário tomar atitudes, como as ações afirmativas, com intenção de equilibrar essa equação. Mas esse equilíbrio não pode ter como foco somente o acesso ao ensino superior, ele deve pensar também todo o processo de escolarização, garantindo que todas as crianças e todos os jovens e adultos tenham uma educação pública de qualidade. 
A lei de cotas é percebida pelos entrevistados como um primeiro passo na busca pela justiça educacional, mas alguns depoimentos indicam a necessidade de permanente problematização de conceitos, como igualdade, diferença, equidade, mérito, justiça e democracia. Alguns participantes apresentaram discursos marcados por ambiguidade no tocante ao mérito e a questões como igualdade perante a lei, diferenças étnicas (indígenas, negros, brancos) e desigualdades sociais vivenciadas pelos estudantes de classes populares (escolarização integral ou parcial na rede pública, renda per capita baixa, necessidade de exercer atividade remunerada para dar continuidade aos estudos, etc.). Os participantes da pesquisa posicionaram-se abertamente a favor das cotas sociais (para estudantes com baixa renda e oriundos de escolas públicas), mas a postura não foi tão enfática com relação às cotas raciais.

Essas ambiguidades podem ser compreendidas como influência de ideologias e discursos meritocráticos e racistas que são amplamente veiculados nos meios de comunicação de massa e, de certo modo, assimilados pelos estudantes. $\mathrm{O}$ vestibular tradicional instiga o mérito conquistado pelo esforço individual; ainda que haja reservas de vagas, há também a nota de corte que, se não alcançada, impede o ingresso na universidade. No entanto, em vez de visibilizar o que foi alcançado pelo estudante cotista, o discurso ideológico antidialógico ressalta a competitividade e parte da lógica da negatividade - centrando-se na falta, isto é, no que ainda não foi atingido. Por meio desse mecanismo, visa a inferiorizar o estudante cotista, de modo a culpabilizá-lo por ousar ocupar um lugar que historicamente lhe fora negado. Não é à toa que muitos estudantes beneficiados com o programa de cotas apresentam percepções ambíguas e conflitantes a respeito dessa iniciativa, temendo serem hostilizados no meio universitário.

É preciso lembrar que ações afirmativas enfrentam resistências entre aqueles que já assimilaram a ideologia da valorização do mérito individual e, ambos, alunos cotistas e não-cotistas, compartilham da mesma ideologia. O ingresso na universidade por meio de Cotas pode ser entendido como um atestado público de incapacidade e demérito (GUARNIERI; MELO-SILVA, 2010, p. 488).

A meritocracia ainda vigente é propagada nos discursos acadêmicos por meio de práticas homogeneizadoras, como o vestibular, por exemplo, o que pode dificultar o processo de afirmação das diferenças e de construção da autoimagem de estudantes cotistas recém-chegados às arenas políticas universitárias, haja vista que a perspectiva meritocrática centraliza suas lentes na dimensão individual, enquanto ofusca os coletivos, os movimentos e as práticas sociais nos quais os sujeitos também educam e educam-se. 
Destarte, para concretizar a justiça educacional, é preciso fazer frente aos discursos meritocráticos e lançar mão do critério de equidade, ou seja, tecer olhares e práticas acadêmicas que considerem as condições existenciais de cada sujeito. Não há como discutir igualdade ou mérito, sem propiciar condições existenciais para que todos os sujeitos possam participar, gozar de seus direitos e exercer controle social. Nesse ponto, os participantes da pesquisa afirmaram que não basta democratizar o ensino superior, é necessário também dar continuidade ao processo de democratização da educação básica, por meio de ações que promovam melhorias na qualidade da educação ofertada na escola pública.

A diferença qualitativa entre a educação ofertada na rede pública de ensino e a desenvolvida nas escolas privadas é, portanto, outra questão relevante a ser retomada e aprofundada nos debates sobre ações afirmativas no Brasil. Segundo os participantes da pesquisa, as desigualdades vivenciadas ao longo da educação básica foram se convertendo em obstáculos que dificultaram o acesso ao ensino superior, levando tais sujeitos a demandarem a reserva de vagas preconizada na lei de cotas.

A luta pela democratização do acesso ao ensino superior público é necessária, mas não suficiente para garantir a permanência dos beneficiados por medidas compensatórias. Haas e Linhares (2012) ressaltam que a discussão sobre o sistema de cotas não pode se limitar ao ingresso dos estudantes cotistas no ensino superior público, deve abarcar também a questão da permanência deste público nos cursos superiores.

Não basta propiciar o acesso, pois é necessário conferir, após o ingresso, igualdade de condições de permanência do estudante no ensino superior público, já que dificilmente os indivíduos deste contingente estão em igualdade de condições no que tange à questão socioeconômica. Do contrário, teria a universidade que admitir o considerável risco de evasão desse grupo de beneficiados por falta de condições sociais, econômicas e intelectuais (HAAS; LINHARES, 2012, p. 853).

Promover condições de permanência para cotistas é fundamental para minimizar a evasão escolar no ensino superior brasileiro. Outro aspecto a ser enfrentado pelas instituições é a falta de condições financeiras desses estudantes para permanecer no curso; a criação de condições de acesso deve prever investimentos em programas de ações de acompanhamento e apoio acadêmico aos estudantes que ingressam pelo sistema de cotas. Nesse sentido, ressalta-se a relevância da constituição de equipes multidisciplinares, compostas por profissionais da assistência social, da pedagogia e da psicologia, aptos a promover o acolhimento e o acompa- 
nhamento da vida acadêmica de estudantes cotistas, a fim de mapear suas demandas, criar ações para atender às necessidades identificadas e avaliar tais ações.

Ademais, destaca-se a importância de avaliar o modo como esses estudantes vêm sendo recebidos e acolhidos por seus pares, por docentes e por funcionários das instituições de ensino superior, no intuito de garantir a permanência e fomentar a socialização desses sujeitos, estimulando o estabelecimento de relações mais solidárias, dialógicas e respeitosas entre os estudantes e os demais atores das instituições de ensino.

Os participantes da pesquisa ressaltaram o papel do apoio financeiro (bolsa de estudo, bolsa moradia, bolsa alimentação, etc.) na garantia de sua permanência no curso. A ausência de alojamento no campus onde foi realizada a pesquisa é entendida pelos participantes como um elemento que dificulta a permanência do estudante, o que se evidenciou no trancamento das matrículas por metade dos estudantes cotistas. Os alojamentos estudantis, além de favorecerem o direito à moradia aos estudantes que necessitam desse auxílio, também se configuram como espaços educativos que podem potencializar a socialização e a organização. Sendo assim, é necessário garantir a continuidade do Programa Nacional de Assistência Estudantil e lutar pela ampliação de recursos.

\section{Considerações finais}

A universidade, enquanto espaço intelectual, científico, educativo e político, no entender de Silva (2003), não pode se distanciar de questões que dizem respeito aos direitos humanos. As instituições de ensino superior que reconhecem a diversidade social e econômica da população brasileira, sua pluralidade cultural e racial, e as avaliam como injustas, ao reservarem vagas para segmentos marginalizados e oprimidos, afirmam-se justas, portanto devem expandir seu campo de visão e produção do conhecimento.

Uma instituição, que se disponha a implantar plano de ações afirmativas para a população negra, não pode encará-lo como "proteção a desvalidos", segundo pretendem alguns. É preciso que um plano com tais metas incentive a compreensão dos valores da diversidade social, cultural, racial e, nestes valores, busque apoio para orientar suas ações educativas, de formação de profissionais e de responsável pelo avanço das ciências. Sem dúvida, a universidade, ao prever e executar medidas visando à inclusão de grupos até então deixados à margem, inclui-se na sociedade, passa a dela fazer parte e assume compromisso com ela, já que deixa de atender unicamente aos interesses de um único segmento até então privilegiado (SILVA, 2003, p. 48). 
As universidades que aderem às ações afirmativas, ao tocarem na estrutura das desigualdades objetivando promover equidade entre grupos marginalizados, além de ampliarem o acesso ao ensino superior, podem representar a busca por novas maneiras de pensar e de produzir conhecimento, construindo, assim, novos modos de ser universidade no Brasil e criando oportunidades democráticas de educação que garantam possibilidades de formação a todos os brasileiros.

A formação universitária é compreendida "como possibilidade de enfrentar, superar intolerâncias, o que implica buscar meios de suprimir desigualdades seculares" (SILVA, 2003, p. 52). Destarte, a relevância social de ações afirmativas como a lei de cotas não reside apenas na ampliação do acesso ao ensino superior por parte de grupos populares, mas, sobretudo, em suscitar o debate acerca da necessária luta pela descolonização de saberes e poderes no interior das universidades.

$\mathrm{O}$ ingresso de estudantes que pertencem a grupos populares no ensino superior tem descortinado temas, experiências e condições existenciais, até pouco tempo, ignorados nas universidades. Ratificando esse entendimento, Eckhardt (2018) considera que as histórias de vida e as trajetórias de formação de estudantes populares permitem o desvelamento de múltiplas formas de subalternização, como expropriação, desigualdade e silenciamento, as quais precisam ser narradas e problematizadas no ensino superior. Essa problematização, por sua vez, favorece o questionamento da matriz curricular eurocêntrica que, historicamente, vem encobrindo e invisibilizando outros modos de ser, de existir, de ler o mundo e de construir conhecimentos (DUSSEL, 1993).

As tensões e os conflitos que emergem do debate sobre as ações afirmativas refletem as disputas políticas em torno de questões históricas, como: a educação é direito de todos ou privilégio de alguns grupos seletos? A quem e a que serve a educação? A educação deve se colocar a serviço da adaptação ou da transformação social? Que saberes devem ser incorporados nos currículos? Essas questões não devem ser tomadas como barreiras intransponíveis ou como justificativa para suprimir as ações afirmativas, pelo contrário, a problematização de tais questionamentos é que possibilitará o desvelamento de inéditos viáveis ${ }^{4}$.

"O diálogo é, portanto, o indispensável caminho", diz Jaspers, "não somente nas questões vitais para nossa ordenação política, mas em todos os sentidos do nosso ser. Somente pela virtude da crença, contudo, tem o diálogo estímulo e significação: pela crença de que somente chego a ser eu mesmo quando os demais também cheguem a ser eles mesmos" (FREIRE, 1975, p. 108). 
O diálogo com estudantes cotistas acerca de suas percepções sobre a lei de cotas, no contexto desta pesquisa, possibilitou compreender que as ações afirmativas se configuram como um dos passos no movimento permanente em busca das justiças social e educacional, posto que, além de promover a democratização do acesso ao ensino superior, tem ampliado as reflexões e fomentado debates acerca das marcas da colonialidade ${ }^{5}$ que ainda perduram nas instituições de ensino. O grande potencial dessa lei reside na ampliação desse debate e na mobilização e no engajamento consequentes de diferentes sujeitos na busca pela superação dessas marcas e pela descolonização dos saberes.

\section{Notas}

1 O grupo é formado por pesquisadores, gestores e profissionais de diferentes regiões do país com experiência em políticas de educação superior e tem por objetivos acompanhar e avaliar os debates sobre a expansão e a democratização da educação superior no Brasil e intervir neles. Mais informações podem ser encontradas em: http://flacso.org.br/?page_id=7785.

2 A respeito da assistência estudantil, consultar análise minuciosa da execução do PNAES nos IFs elaborada por Prada e Surdine (2018) e histórico da assistência estudantil em artigo de Dutra e Santos (2017).

3 Apesar de o termo "ação afirmativa" ser cunhado, originalmente, nos Estados Unidos, a Índia foi o primeiro país a adotar o sistema de cotas raciais no ingresso ao ensino superior, na década de 1930, com a finalidade de beneficiar os Dalits (casta mais baixa e discriminada da Índia). Desde a Constituição de 1949 até hoje, as cotas estão em vigor na Índia, sendo válidas no serviço público, na educação e nos órgãos estatais. De acordo com Carvalho (2005 apud SILVA, Paula; SILVA, Patrícia, 2012), a Índia é um exemplo positivo da utilização do sistema de cotas, pois em 1950 apenas $1 \%$ dos Dalits tinha curso superior e, em 2005, esse percentual subiu para $12 \%$.

4 Conceito formulado por Freire (1970) para designar uma situação nova e ainda não experimentada, mas que pode ser obtida pela ação dos seres humanos no mundo a ser transformado (SOUSA, 2018, p. 328).

5 Conceito introduzido por Aníbal Quijano (final da década de 1980, início da década de 1990) para designar a lógica subjacente da fundação e o desdobramento da civilização ocidental, da qual colonialismos históricos têm sido uma dimensão constituinte, mas minimizada (MIGNOLO, 2017).

\section{Referências}

ARROYO, Miguel G. O direito à educação e a nova segregação social e racial: tempos insatisfatórios? Educação em Revista, Belo Horizonte, v. 31, n. 3, p. 15-47, set. 2015.

BOURDIEU, Pierre. A economia das trocas simbólicas. 5. ed. São Paulo: Perspectiva, 2003.

BRASIL. Decreto $n^{\circ}$ 12.711, de 29 de agosto de 2012. Dispõe sobre o ingresso nas universidades federais e nas instituições federais de ensino técnico de nível médio e dá outras providências. Diário Oficial da República Federativa do Brasil, Brasília, DF, 30 ago. 2012a.

BRASIL. Ministério da Educação. Portaria Normativa $n^{\circ}$ 18, de 11 de outubro de 2012. Dispõe sobre a implementação das reservas de vagas em instituições federais de ensino de que tratam a Lei $\mathrm{n}^{\circ}$ 12.711, de 29 de agosto de 2012 , e o Decreto $\mathrm{n}^{\circ}$ 7.824, de 11 de outubro de 2012. Diário Oficial da República Federativa do Brasil, Brasília, DF, 15 out. 2012b. 
BRASIL. Decreto no. 7.824: Regulamenta a Lei $n^{\circ}$ 12.711, de 29 de agosto de 2012. Dispõe sobre o ingresso nas universidades federais e nas instituições federais de ensino técnico de nível médio. Brasília, 2012c.

BUCCI, Maria Paula D.; MELLO, Paula B. Democratização e acesso à educação superior. GEA Opinião, Rio de Janeiro, n. 7, parte I, p. 1-4, mar. 2013.

DUARTE, Rosália. Entrevistas em pesquisas qualitativas. Educar, Editora UFPR, Curitiba, n. 24, p. 213-225, 2004.

DUSSEL, Enrique. 1492: o encobrimento do outro. Petrópolis: Vozes, 1993.

DUTRA, Natália G. R.; SANTOS, Maria de Fátima S. Assistência estudantil sob múltiplos olhares: a disputa de concepções. Ensaio: Avaliação e Políticas Públicas em Educação, Rio de Janeiro, v. 25, n. 94, p. 148-181, mar. 2017.

ECKHARDT, Fabiana. As classes populares no curso de pedagogia: descobrindo-se periferia. Revista de Ciências da Educação, Americana, n. 41, p. 149-162, out. 2018.

FRASER, Nancy. Reenquadrando a justiça em um mundo globalizado. Lua Nova, São Paulo, n. 77, p. 11-39, 2009.

FREIRE, Paulo. Educação como prática da liberdade. 5. ed. Rio de Janeiro: Paz e Terra, 1975.

FREIRE, Paulo. Pedagogia do oprimido. Rio de Janeiro: Paz e Terra, 1970.

GISI, Maria Lourdes. A educação superior no Brasil e o caráter de desigualdade do acesso e da permanência. Revista Diálogo Educacional, Curitiba, v. 6, n. 17, p. 97-112, jan./abr. 2006.

GUARNIERI, Fernanda V.; MELO-SILVA, Lucy L. Perspectivas de estudantes em situação de vestibular sobre as cotas universitárias. Psicologia \& Sociedade, Florianópolis, v. 22, n. 3, p. 486-498, dez. 2010.

HAAS, Celia Maria; LINHARES, Milton. Políticas públicas de ações afirmativas para ingresso na educação superior se justificam no Brasil? Revista Brasileira de Estudos Pedagógicos, v. 93, n. 235, p. 836-863, dez. 2012.

INSTITUTO NACIONAL DE ESTUDOS E PESQUISAS EDUCACIONAIS ANÍSIO TEIXEIRA. Censo da educação superior: 2011 - resumo técnico. Brasília, 2013.

LIMA, Marcus Eugênio O.; NEVES, Paulo Sérgio C.; SILVA, Paula B. A implantação das cotas na universidade: paternalismo e ameaça à posição dos grupos dominantes. Rev. Bras. de Educação, Rio de Janeiro, v. 19, n. 56, p. 141-163, jan./mar. 2014.

MIGNOLO, Walter D. Colonialidade: o lado mais escuro da modernidade. Revista Brasileira de Ciências Sociais, São Paulo, v. 32, n. 94, e329402, 2017.

MOEHLECKE, Sabrina. Ação afirmativa: história e debates no Brasil. Cad. Pesqui., São Paulo, n. 117, p. 197-217, nov. 2002.

MUNANGA, Kabengele. Políticas de ação afirmativa em benefício da população negra do Brasil: um ponto de vista em defesa de cotas. Sociedade e Cultura, Goiânia, v. 4, n. 2, p. 31-43, jul./ dez. 2001. 
NEVES, Paulo S. C.; LIMA, Marcus Eugênio O. Percepções de justiça social e atitudes de estudantes pré-vestibulandos e universitários sobre as cotas para negros e pardos nas universidades públicas. Revista Brasileira de Educação, Rio de Janeiro, v. 12, n. 34, p. 17-38, abr. 2007.

PEREIRA, Thiago I.; MAY, Fernanda; GUTIERREZ, Daniel. O acesso das classes populares ao ensino superior: novas políticas, antigos desafios. Revista Pedagógica, Chapecó, v. 16, n. 32, p. 117-140, jan./jul. 2014.

PRADA, Talita; SURDINE, Mônya Carla C. A assistência estudantil nos Institutos Federais de Educação, Ciência e Tecnologia. SER Social, Brasília, v. 20, n. 43, p. 268-289, 13 nov. 2018.

QUEIROZ, Delcele M.; SANTOS, Jocelio T. Sistema de cotas: um debate. Dos dados a manutenção de privilégios e de poder. Educação \& Sociedade, CEDES, Campinas, v. 27, n. 96 especial, p. 717-737, out. 2006.

SILVA, Paula B.; SILVA, Patrícia. Representações sociais de estudantes universitários sobre cotas na universidade. Fractal: Revista de Psicologia, Rio de Janeiro, v. 24, n. 3, p. 525-542, set./dez. 2012.

SILVA, Petronilha Beatriz G. Negros na universidade e produção de conhecimento. In: SILVA, Petronilha Beatriz G.; SILVÉRIO, Valter Roberto (org.). Educação e ações afirmativas: entre a injustiça simbólica e a injustiça econômica. Brasília: Instituto Nacional de Estudos e Pesquisas Educacionais Anísio Teixeira, 2003. p. 43-54.

SOUSA, Fabiana R. Legado freireano, feminismos e prostituição: desvelando o político-pedagógico na pesquisa em educação. Educação Unisinos, São Leopoldo, v. 22, n. 4, p. 324-333, out./ dez. 2018.

SOUZA, Andreliza Cristina.; BRANDALISE, Mary Ângela T. Democratização, justiça social e igualdade na avaliação de uma política afirmativa: com a palavra, os estudantes. Ensaio: Avaliação e Políticas Públicas em Educação, Rio de Janeiro, v. 23, n. 86, p. 181-212, fev. 2015. 